\title{
LEER Y ESCRIBIR EL MUNDO CON MATEMÁTICAS: REFLEXIONANDO SOBRE LOS ESTEREOTIPOS Y LA VISIBILIDAD DE LA COMUNIDAD LGBT +
}

\author{
Denner Dias Barros \\ dennerdias12@,gmail.com \\ https://orcid.org/0000-0002-8108-022X \\ Universidade Estadual Paulista - Unesp \\ Brasil
}

Recibido: 2020-10-18; Aceptado: 2020-11-30

\section{Resumen}

Vivimos en una sociedad marcada por injusticias basadas en cuestiones sociales y estereotipos producidos para ciertos grupos y que dicen cómo deben ser y qué deben hacer. La violencia que sufren estas personas son barreras que limitan posibilidades que pueden y deben romperse, mostrando que otras realidades son posibles. Las matemáticas no son neutrales y pueden romper con los estereotipos existentes o ayudar a reproducirlos. Cabe mencionar que tiene su carácter transformador y debe ser considerado como con el poder de promover una lectura del mundo, echar una mirada crítica a la sociedad y, también, realizar transformaciones, es decir, la escritura del mundo. El objetivo de este trabajo fue comprender cómo el tema de la visibilidad y los estereotipos se puede investigar con las matemáticas y discutir en un espacio de la comunidad LGBT + en la búsqueda de superar las injusticias y ampliar las posibilidades de vida. Pudimos darnos cuenta de que la comunidad LGBT + todavía está muy marcada por estereotipos y que una mirada crítica a la forma en que ha sido retratada es importante para que se lleven a cabo las transformaciones.

Palabras clave: Educación Matemática Crítica. Visibilidad. Estereotipos. Comunidad LGBT +. Leer y escribir el mundo con matemáticas.

\section{LER E ESCREVER O MUNDO COM A MATEMÁTICA: REFLETINDO SOBRE ESTEREÓTIPOS E A VISIBILIDADE DA COMUNIDADE LGBT+}

\section{Resumo}

Vivemos em uma sociedade marcada por injustiças pautadas em questões sociais e em estereótipos produzidos para determinados grupos e que dizem como devem ser e o que devem fazer. As violências sofridas por estas pessoas são barreiras limitantes de possibilidades que podem e devem ser rompidas mostrando que outras realidades são possíveis. A matemática não é neutra e, pode tanto romper com estereótipos existentes, como ajudar a reproduzi-los. Vale ressaltar que ela possui seu caráter transformador e deve ser considerada como tendo potência para promover uma leitura de mundo lançando um olhar crítico para a sociedade e, também, para realizar transformações, ou seja, a escrita do mundo. O objetivo deste trabalho foi compreender como a questão da visibilidade e dos estereótipos pode ser investigada com a matemática e discutida em um espaço da comunidade LGBT+ na busca da superação de injustiças e na ampliação de possibilidades de vida. Conseguimos perceber que a comunidade LGBT+ ainda é muito marcada por estereótipos e que lançar um olhar crítico para a forma como ela tem sido retratada é importante para que transformações possam ser realizadas.

Palavras-chave: Educação Matemática Crítica. Visibilidade. Estereótipos. Comunidade LGBT+. Leitura e escrita do mundo com a matemática. 


\title{
READ AND WRITE THE WORLD WITH MATHEMATICS: THINKING ABOUT STEREOTYPES AND THE VISIBILITY OF THE LGBT+ COMMUNITY
}

\begin{abstract}
We live in a society marked by injustices based on social issues and stereotypes produced for certain groups and which say how they should be and what they should do. The violence suffered by these people are barriers that limit possibilities that can and must be broken showing that other realities are possible. Mathematics is not neutral and can either break with existing stereotypes or help to reproduce them. It is worth mentioning that it has its transforming character and should be considered as having the power to promote a reading of the world, casting a critical eye on society and, also, to carry out transformations, that is, the writing of the world. The objective of this work was to understand how the issue of visibility and stereotypes can be investigated with mathematics and discussed in a space of the LGBT + community in the search for overcoming injustices and expanding life possibilities. We can see that the LGBT+ community is still very marked by stereotypes and that taking a critical look at the way it has been portrayed is important so that transformations can be carried out.
\end{abstract}

Keywords: Critical Mathematics Education. Visibility. Stereotypes. LGBT + community. Reading and writing the world with mathematics.

\section{Considerações Iniciais}

Chimamanda Ngozi Adichie é uma escritora Nigeriana nascida em 1977. Foi para os

Estados Unidos aos 19 anos para estudar comunicação na Universidade Drexel na Filadélfia e concluiu seus estudos em Comunicação e Ciências Políticas em Estern Connecticut State University.

Em sua obra "O perigo de uma história única" relata sobre a visão estereotipada que percebeu que as pessoas nos Estados Unidos tinham do continente africano. Ouviu de sua colega de quarto que ela estava espantada com sua fluência no Inglês, mesmo esta sendo uma das línguas oficiais da Nigéria. As constantes histórias de pobreza, guerras civis e mortes eram atribuídas às origens de Chimamanda, por pessoas que não conheciam seu país de nascimento, mas que ao longo de suas vidas tiveram acesso apenas a versões diferentes de uma única história sobre a África. A autora relata que uma vez apresentou um trabalho para um professor universitário que alegou que seu romance não era "autenticamente africano".

Eu estava bastante disposta a admitir que havia diversas coisas erradas com o romance e que ele fracassava em vários aspectos, mas não chegara a imaginar que fracassava em alcançar algo chamado "autenticidade africana". $\mathrm{Na}$ verdade, eu não sabia o que era autenticidade africana. O professor me disse que meus personagens pareciam demais com ele próprio, um homem instruído de classe média: eles dirigiam carros, não estavam passando fome; portanto, não eram autenticamente africanos (ADICHIE, 2019, p.20-21). 
Para ela, produzir uma história única é algo muito perigoso, pois está relacionado com a ideia de poder, afinal esta história é contada por alguém que tem este poder de não apenas contala, mas de torna-la definitiva. "É assim que se cria uma história única: mostre um povo como uma coisa, uma coisa só, sem parar, e é isso que esse povo se torna" (ADICHIE, 2019, p.22).

Estas histórias únicas criam estereótipos. Para Ribeiro (2018), “estereótipos são generalizações impostas a grupos sociais específicos, geralmente aqueles oprimidos” (p.56). Em uma sociedade estabelecida dentro destas relações de poder, criam-se papéis que determinados grupos precisam desempenhar e não podem estar em outros. Por exemplo, a ideia de que mulheres são naturalmente maternais e precisam cuidar da casa e dos filhos pode gerar discriminação a este grupo no mercado de trabalho.

O mesmo ocorre com pessoas negras: a ideia de que toda negra sabe sambar ou de que todo negro é bom de bola (desde que não seja goleiro) são estereótipos que têm por finalidade nos manter no lugar que a sociedade racista determina (RIBEIRO, 2018, p.56).

Estamos sempre contando histórias, até mesmo nas aulas de matemática quando decidimos discutir sobre algum conceito, elaboramos um enunciado de um problema ou queremos contextualizar determinado assunto. É importante ressaltar que essas histórias podem ser construídas dentro ou fora dos estereótipos, seja para limitar, caluniar, diminuir ou para humanizar, construir e ampliar. Partindo destas considerações, podemos refletir: que história(s) estamos contando em nossas aulas de matemática? Estamos contando uma história única ou mostrando que outras são possíveis?

\section{Um mundo que pode ser lido e escrito (com a Matemática)}

Todo tipo de ação tem qualidades, sejam elas arriscadas, benevolentes, promissoras, egoístas, dentre outras. Sendo assim, são necessárias que sejam lançadas avaliações e reflexões sobre as demandas éticas dessas ações (Ravn e Skovsmose, 2019). Nesse sentido, quando decisões são tomadas, são fabricados fatos, ficções, riscos e ilusões que não são neutros.

A matemática também possui essa característica. Para Ravn e Skovsmose (2019), todas as ações baseadas na matemática devem considerar que apesar de uma aparente neutralidade, quando pensamos em produções que não deixam de ser sociais, estão carregadas de intencionalidades. Um exemplo apresentado pelos autores é sobre o mecanismo de pesquisa do 
Google, um dos mais eficientes e utilizados no mundo, que faz uso de ferramentas da álgebra linear e, através do seu sistema PageRank classifica e faz busca em sites através de palavraschave. Entretanto, os algoritmos usados para classificar e definir as prioridades de quais dentre os bilhões de sites devem ser apresentados como os primeiros resultados não são conhecidos por grande parte dos usuários deste sistema.

Os autores nos esclarecem sobre como este processo ocorre:

O Google pesquisa todos os sites acessíveis e armazena as informações disponíveis. Essas informações são organizadas em uma matriz gigante n x n. O modelo PageRank identifica se há links entre duas páginas na Internet e calcula o número de páginas apontadas para uma página específica na web. Ao mesmo tempo, o modelo fornece a cada página uma classificação com relação à importância, que se refere a quantos visitantes uma página tem e quão "conectada" a página está a outras páginas, entre outras coisas. $\mathrm{O}$ conteúdo da matriz é extremamente abrangente e seria impossível trabalhar se não fosse pelos muitos zeros que ela contém. Os zeros são um resultado do fato de a grande maioria das páginas na rede não estar vinculada. Quando alguém está pesquisando no Google, as palavras-chave são comparadas com o conteúdo real de, digamos, um milhão de páginas da web e são classificadas de acordo com o modelo do PageRank. Essa classificação é baseada no cálculo da matriz e o resultado é a ordem pela qual as páginas da web são apresentadas a pessoa que pesquisa (RAVN E SKOVSMOSE, 2019, p.161, tradução minha).

Apesar de serem apresentadas técnicas matemáticas avançadas bem definidas, a forma como a empresa constrói este algoritmo de priorização dos resultados tem seus interesses próprios e financeiros. Neste caso, não deixa de ser produzido um cenário que pode ser positivo ou negativo dependendo das perspectivas que se tem sobre o assunto pesquisado.

Um exemplo acerca desta influência sobre os resultados de suas buscas foi veiculado na mídia no ano de 2019. De acordo com uma reportagem ${ }^{1}$ do jornal O Globo, o Google realizou uma mudança no seu algoritmo para a busca pelo termo lesbienne (lésbica, em francês). Anterior a mudança, a simples busca por esta única palavra mostrava em seus primeiros resultados sites adultos com conteúdo que provocava uma hipersexualização deste grupo. Este tipo de resultado é consequência de uma fetichização feita sobre o relacionamento lésbico.

Este é um exemplo das muitas dificuldades que a comunidade LGBT+ (Lésbicas, Gays,

\footnotetext{
${ }^{1}$ Disponível em: https://oglobo.globo.com/celina/google-muda-algoritmo-para-que-palavra-lesbica-nao-sejaassociada-pornografia-nas-buscas-23866924. Acesso em: 21 mar. 2020.
} 
Transexuais, Transgêneros, Travestis e mais) sofre. O Brasil é recordista no número de mortes por crimes de ódio a esta população. O Grupo Gay Bahia retratou através de seu último relatório que no ano de 2018 foram registradas 420 mortes. Estas foram produzidas pela LGBTfobia que tem suas origens em estereótipos e violências construídos socialmente contra esta população.

Esta realidade necessita de transformações. Um primeiro passo é compreendê-la e conseguir ferramentas para enxergar outras possibilidades de constituição dessa sociedade. Olhar e refletir sobre estas questões podem ser entendidos como possibilidades de ler o mundo.

Paulo Freire realizou seu trabalho de alfabetização considerando a necessidade de uma educação crítica e emancipadora. Partindo de experiências durante sua vida como educador, pensou na questão da alfabetização como sendo uma forma de favorecer a todos a possibilidade de serem atores da realidade. Para o autor,

(...) me parecia profunda injustiça haver homens e mulheres que não sabiam ler ou escrever. A injustiça que por si só o analfabetismo representa tem implicações mais graves, tal como a de os analfabetos se verem anulados por sua incapacidade de tomar decisões sozinhos, votar e participar do processo político. Isso me parecia ser absurdo. Ser analfabeto não elimina o bom senso para escolher o que é melhor para si, nem para escolher os governantes melhores (ou menos ruins) (FREIRE E MACEDO, 2015, p.200).

Para os estudantes realizarem escolhas mais conscientes e conseguir compreender o mundo em que vivem, Freire discute sobre uma alfabetização através do contexto do educando, considerando que ele tem tanto a ensinar quanto a aprender. Ser alfabetizado, para Freire é estar presente na luta pela própria voz e por um futuro mais promissor em uma sociedade onde as posições sociais são estabelecidas por relações de poder. O ato de ler, para ele, é um ato de resistência.

Gutstein $(2003 ; 2006)$, pautado nas ideias de Freire, lança um olhar para a matemática nesta perspectiva de representar uma possibilidade de ler e escrever o mundo. Para o autor, ler o mundo com a matemática significa entendê-la como tendo potência para compreender a realidade de uma maneira mais ampla. Deste modo, usar a matemática para entender as injustiças da sociedade e adotar uma postura crítica frente às desigualdades é ler este mundo com a matemática. Além disso, é possível que mudanças sejam realizadas pautadas nesta leitura. Quando são feitas ações que buscam uma transformação social podemos dizer que estamos escrevendo o mundo e, se neste processo a matemática for importante, essa escrita pode ser dita 
sendo feita com a matemática.

Um trabalho que foi realizado neste sentido foi o de Brito (2013). Ele propôs que seus estudantes do $9^{\circ}$ ano do Ensino Fundamental da Rede Pública Municipal de Ensino em Juiz de Fora (MG) investigassem como se dá a presença das pessoas negras em revistas. $\mathrm{O}$ autor queria compreender se as crianças negras e brancas eram retratadas de forma diferente na mídia impressa. O primeiro passo foi selecionar em revistas fotos de crianças. Os estudantes conseguiram coletar 41 fotos, das quais 36 eram de crianças brancas $(87,80 \%)$ e cinco crianças negras $(12,20 \%)$. Apenas neste primeiro exercício fica evidente que a visibilidade é muito maior para as crianças brancas.

Um segundo processo proposto por Brito foi que identificassem se essas crianças estavam sendo registradas em contextos positivos (brincando, felizes) ou negativos (sofrendo algum tipo de violência). Seus estudantes entenderam que das 36 crianças brancas, 35 estavam em situações positivas (97,22\%) e apenas uma em negativa (2,78\%). Das cinco crianças negras, três estavam em situações positivas $(60 \%)$ e duas em negativas (40\%). No ano seguinte, ele desenvolveu a mesma atividade com outra turma e percebeu que $81 \%$ das fotos eram de crianças brancas, $15 \%$ de negras e $4 \%$ de outras etnias. Além disso, apenas $4 \%$ das brancas estavam em situações negativas, enquanto para as crianças negras 34\% estavam na mesma situação.

Com este trabalho, o autor reflete sobre os estereótipos lançados sobre a população negra que são muito presentes na mídia e que reforçam o quanto esta população é retratada em situações negativas e de maior vulnerabilidade reforçando um discurso racista e de limitação de possibilidades para estas pessoas que muitas vezes são retratadas em posições que reforçam que este grupo só pode ocupar determinados espaços e não outros.

Os estereótipos mostrados na TV dão conta sobretudo nas novelas globais do lugar de inferioridade que nos referimos, negros e negras não se preocupam apenas com samba, futebol, carnaval e capoeira, como faz pensar quem assiste essas produções televisivas, nem tão pouco tem inclinações artísticas naturais para o desempenho apenas em papéis que figuram como mordomos, choferes e empregadas domésticas, ainda que estas profissões sejam honrosas (BRITO, 2013, p.5).

Este tipo de discussão proposta por Gutstein e que se evidencia na pesquisa de Brito pode ser uma iniciativa maior para motivar que transformações sejam feitas através de uma leitura consciente do mundo. Uma vez que desigualdades são constatadas na sociedade, temos 
ferramentas para apontar que a situação necessita ser mudada e, partindo desses pressupostos, transformações podem ser realizadas.

Neste trabalho, compreendemos que o discurso e a imagem atribuída à comunidade LGBT+ é estereotipada e preconceituosa, muitas vezes de forma velada e em outras vezes de forma explícita, assim como acontece com a imagem de pessoas negras veiculadas na mídia. A leitura deste contexto é essencial para que estas pessoas possam escrever um novo caminho. Para isso, acreditamos que a matemática pode se configurar como uma ferramenta potente.

A partir do contexto apresentado, surgem questões como: o que poderia significar a leitura e escrita de mundo com a matemática para a comunidade LGBT+? Que estereótipos são produzidos para esta população e como superá-los? Na sequência buscaremos discutir sobre alguns enfrentamentos da população LGBT+ no Brasil.

\section{Estereótipos e violências contra a população LGBT+: Um contexto de resistência}

A população LGBT+ tem sido vítima de muita violência em nosso país, como retratamos anteriormente. Este tipo de violência que também é intensificado pela criação de estereótipos relacionados a este público, tem promovido discriminação em diversos âmbitos, inclusive dentro de suas próprias casas. Infelizmente, um cenário comum é da expulsão de jovens LGBT+ de suas casas quando decidem expressar sua identidade ou expressão de gênero e/ou sua sexualidade para suas famílias.

De acordo com a Organização das Nações Unidas (ONU), a reprovação familiar acontece pelo preconceito promovido, muitas vezes, pela intolerância religiosa e pelos estereótipos que promovem uma ligação direta entre esse público a questões relacionadas com doenças sexualmente transmissíveis, drogas e prostituição. Sendo assim, o que acontece com estas pessoas quando são expulsas de suas casas?

Machado (2015) aponta que os motivos para que as pessoas LGBT+ cheguem a uma situação de rua são muitas, como os conflitos familiares, falta de formação profissional, homofobia em diversos âmbitos, como no trabalho, dentre outros.

De acordo com Campos e Pires (2016) houve um grande aumento no número de pessoas em situação de rua no Brasil, passando de 50 mil no ano de 2008 para 101.854 em 2016. O censo da cidade de São Paulo em 2016 mostrou que neste município, 10\% do público se identificava como tendo uma orientação não heterossexual. 
Em uma sociedade capitalista com desigualdades, preconceito, desemprego, pobreza e violência, muitas pessoas enfrentam diariamente uma luta por sobrevivência estando nessa condição social. Apesar desta ser uma realidade de todas as pessoas nesta situação independente de sua sexualidade e gênero, as pessoas LGBT+ tem um agravante que é decorrente de preconceitos específicos gerados na sociedade e na família das pessoas deste grupo (MACHADO, 2015).

Além disso, a própria comunidade LGBT+ é muito heterogênea e necessita que suas diferenças sejam levadas em consideração, como afirma Garcia (2007):

Em seu conjunto, portanto, os processos que envolvem as (auto) representações das homossexualidades de rua mostram a necessidade de um diálogo com as especificidades destas, tomando o cuidado para não tomá-las como um todo homogêneo e para não interpretá-las a partir dos referenciais identitários típicos dos segmentos de renda médios e altos. Pode-se afirmar que tais processos trazem questionamentos inclusive sobre o campo conceitual presente no campo de estudos de gênero e sexualidade, como no caso da diferenciação comumente feita entre "orientação sexual" e "identidade de gênero", que se mostra inadequada para se interpretar as vivências das pessoas LGBT em situação de rua (GARCIA, 2007, p. 32).

Sendo assim, é importante que olhemos para cada indivíduo como tendo suas características provenientes do grupo ao qual fazem parte, mas também suas particularidades e identitárias em qualquer contexto. Machado (2015) aponta que uma das principais demandas que pode auxiliar este grupo é a reinserção econômica promovida pela inserção no mercado de trabalho para terem o direito à moradia, além de outras possibilidades.

Iniciativas foram feitas em busca de minimizar a difícil situação das pessoas LGBT+ que são expulsas de suas casas. Temos projetos relacionados com a saúde deste público e trabalhos da área de serviço social buscando políticas para o enfrentamento destes problemas. A criação de casas de acolhimento tem sido uma medida tomada para as pessoas em situação de rua. Pensando na comunidade LGBT+ também foram criadas casas específicas para este público.

Como um exemplo, podemos citar a Casa 1, localizada na cidade de São Paulo/SP. Ela possui dois ambientes: a casa para acolhimento e o galpão, onde são realizadas atividades educacionais para os acolhidos e demais pessoas da comunidade pensando na formação destas pessoas, inclusive para discussões sobre gênero e sexualidade.

A pesquisa de doutorado a qual este artigo está vinculado foi realizada em uma casa de 
acolhimento LGBT+ da cidade de Presidente Prudente/SP, chamada Casassa. Este espaço foi fundado em 2017, após atividades da Semana da Diversidade realizada na cidade, onde surgiu a demanda de terem um espaço contínuo para acolher pessoas LGBT+. Entretanto, para eles, o acolhimento é entendido em dois aspectos: como possibilidade de moradia e, também, para realização de discussões sobre as questões da própria comunidade.

Todo o trabalho realizado é voluntário. A equipe conta com professores, psicólogos, advogados e demais profissionais responsáveis por tarefas distintas dentro da casa, organizada por grupos de trabalho.

Neste sentido, buscou-se compreender como este local poderia se constituir como um espaço de aprendizagem, tanto nas questões de organização e convivência, quanto na construção de um saber de conceitos mais sistematizados. Além disso, houve o interesse em investigar sobre a presença da matemática seguindo a perspectiva da Educação Matemática para Justiça Social, no que diz respeito, especialmente, à leitura e escrita de mundo.

Para isso, a pesquisa realizada entre os meses de agosto e setembro de 2019 foi composta pela presença do pesquisador em todas as atividades promovidas pela casa, como reuniões e bazares para arrecadação de dinheiro. Além disso, foram realizadas entrevistas semiestruturadas com sete voluntários da equipe da Casassa e também duas rodas de conversa com duração média de duas horas e abertas para a comunidade.

Neste artigo, vamos concentrar nossas discussões na temática da segunda roda de conversa que foi a questão dos estereótipos e a visibilidade da comunidade LGBT+. A matemática no contexto desta roda de conversa teve papel importante para compreendermos como este público tem sido retratado e para refletirmos sobre possíveis implicações deste discurso produzido pelas mídias.

\section{A questão dos estereótipos e a visibilidade da comunidade LGBT+}

A roda de conversa em questão foi feita no dia 12 de setembro, com a presença de seis pessoas, incluindo o pesquisador, moradores da Casassa, voluntários e pessoas interessadas da comunidade. Os participantes foram Denner (pesquisador), $\mathrm{Ana}^{2}$, Karla, Klaus, Camila e Nádia. As discussões iniciaram com a música "Triste, louca ou má" da banda Francisco, el Hombre. O clipe e a letra da música acompanharam a sua exibição. Quando questionados sobre a mulher

\footnotetext{
${ }^{2}$ Todos os nomes dos participantes são fictícios.
} 
que é retratada nesta música, os participantes falaram sobre o assunto.

Ana: Parece muito a mulher da família tradicional brasileira. A mulher que cuida da casa, da família e do marido. Ela olha para todo mundo e não olha para si. Ela tem diversos papéis, menos o de ser ela mesma. Ela vive em função dos outros.

Denner: Me parece que ela sofre uma transformação ao longo da música. No começo, quando ela diz sobre "receita cultural", acredito que ela diz dessa visão estereotipada do que se diz que é uma mulher e o papel dela na sociedade. Ela é esposa e mãe, mas não pode ser mulher. Quando ela quer ser mulher e começa a dizer "um homem não me define", "minha carne não me define", ela quer dizer que é muito mais do que isso, mas quando ela faz esse movimento, acaba sendo taxada de "triste, louca ou má".

Karla: Acredito que a nossa geração está crescendo com um pouco mais dessa liberdade, mas se olharmos para os nossos pais e avós, essa é a realidade, da mulher que tem que ficar em casa. É bonito ver essa expressão de que estamos nos libertando. No clipe, achei muito bonita a dança como representação do movimento de libertação. Acho que ainda falta muito, mas quando ouvimos discursos de mulheres que falam que não precisam do feminismo, conseguimos olhar para muita coisa que foi conquistada. Então, conseguimos várias coisas, mas falta muito ainda. O machismo ainda é algo muito forte. Uma coisa que eu vejo, me deixa triste, mas que não falam muito é o quanto o homem sofre com isso, pois ele carrega o peso de ter que ser duro e não poder chorar.

Pesquisador: Vocês conseguem imaginar alguma mulher quando ouvem essa música e pensam nesse movimento de libertação?

Ana: Essa música me lembrou minha mãe, pois ela tem esse discurso de que a mulher serve o marido. Não é uma questão de companheirismo, mas ela deve ser como uma empregada, que tem que lavar as roupas, servir a comida. Tudo feito como uma obrigação. A mulher tem que trabalhar fora e dentro de casa e o marido apenas fora. Para mim ter um companheiro não é sobre isso, mas sobre dividir tarefas e estar junto.

Denner: Neste cenário, é diferente falarmos de mulheres e de mulheres negras?

Ana: Eu vejo a diferença, porque eu posso sofrer por ser mulher e receber salários menores, mas em uma sociedade racista, por 
exemplo, eu posso ter uma qualificação inferior, mas o fato de ser branca pode me dar um emprego no lugar de uma mulher negra. O lugar da mulher negra vista pela sociedade é muitas vezes como sendo empregada doméstica. Ela não é vista muitas vezes como uma mulher que tem potencial para desempenhar outras funções na sociedade. Ela sofreria em dobro, por ser mulher e por ser negra. Durante muito tempo a mulher negra que apareceu nas novelas era a babá, a empregada, o figurante. Raramente você vê uma negra como protagonista. Muitas vezes quando isso acontece é só para reforçar que aquela foi uma história vivida por um negro de maneira pejorativa.

Karla: Isso me faz lembrar da Globeleza. A mulher negra que aparece como um símbolo sexual. O símbolo da mulher brasileira muitas vezes e que é carregada de estereótipo.

(Roda de conversa sobre visibilidade, 2019).

Com esta discussão vemos a força dos estereótipos na limitação de possibilidades para um grupo. Por não enxergarem como sendo possível estar em outros espaços ou viver outras realidades, o preconceito e a discriminação oprimem e reduzem. Essas convenções sociais são muito prejudiciais.

(...) ideias e valores se fixam, uns por convenção, outros por experimentação, outros ainda por ambas, e são compartilhados pelo grupo, em grande escala. Quando se trata de tipos de pessoas, ou melhor, daquilo que é típico, tão reconhecível que até tem nome, no seio de um grupo, estamos defronte de estereótipos culturais (HARKOT-DE-LATAILLE, 2003, p.172).

A autora traz em seu artigo ideias semelhantes às que foram discutidas na roda de conversa. Ela entende que, desde cedo, as pessoas aprendem que "homem não chora" e "mulher é delicada e frágil". Neste sentido, qualquer pessoa que pertença a estes grupos e fogem às regras impostas são vistas com estranhamento e sendo taxadas como erradas.

A leitura do texto "Mulher negra não é fantasia de carnaval" de Ribeiro (2017) foi feita na sequência e em grupo. Este artigo nos ajudou a pensar sobre os estereótipos, lançando um olhar sobre o movimento "Black Face", onde em muitos carnavais as pessoas faziam uso de fantasias e as pessoas brancas pintavam os rostos para representarem "papeis de pessoas negras". Podemos relacionar este fato com o que Brito (2013) nos disse sobre a presença estereotipada das pessoas negras na mídia que são muitas vezes retratadas em determinados trabalhos e não 
em outros. Sobre esta questão, os participantes trouxeram suas perspectivas refletindo sobre um racismo que está enraizado na sociedade.

Camila: É o retrato perfeito da nossa sociedade brasileira, de como somos vistos pelos outros países, mas que também é tão presente aqui. É algo cultural. Temos que ir na raiz do problema para começar a fazer mudanças. Podemos ver como o racismo é forte e está enraizado no nosso país.

Ana: Uma discussão que vi esses dias sobre a escolha da atriz para o filme da "Pequena Sereia". Várias pessoas reclamaram sobre a escolha da atriz, porque ela era negra e ia interpretar uma sereia. Hoje até que é mais comum, mas na minha infância não haviam bonecas negras, por exemplo. Quando se fala em mulher negra, só é interessante para aquela imagem da mulher do carnaval que é sexualizada.

(Roda de conversa sobre visibilidade, 2019).

A discussão continuou com uma reflexão específica sobre a comunidade LGBT+. Do mesmo modo, os participantes trouxeram a questão dos estereótipos, mas também de um exemplo que acharam positivo que foi a contratação de uma atriz transgênero para interpretar uma personagem que também é.

Denner: Agora pensando na comunidade LGBT+, como ela é retratada na mídia?

Karla: Pensando em pessoas, me lembro logo da Pablo Vittar.

Klaus: O Félix da novela “Amor à vida".

Ana: O que é interessante deste personagem é que no começo da novela, ele tinha comportamentos típicos de um homem heterossexual, pois vivia dentro do armário. Quando ele se assume, passa a ser o gay escancarado e estereotipado, com roupa colada, usando a flor na cabeça, com comportamentos escandalosos.

Denner: Nesse caso, vemos a representação de um homem afeminado para quebrar paradigmas ou apenas para o humor?

Ana: O gay aparece muitas vezes como sendo o cabeleireiro, o empregado da madame. Nunca desempenha outros papéis ou constitui família. Parece que ele sempre está de bem com a vida, que não sofre homofobia.

Nádia: Na novela "Bom Sucesso" tem uma personagem trans e a atriz 
que interpreta é uma pessoa trans mesmo. Não tenho acompanhado muito, mas achei interessante.

Klaus: Gostei da forma como ela tem sido retratada. Mostra sobre a dificuldade no mercado de trabalho e o fato dela ter sido demitida por ser trans. Uma realidade que muitos enfrentam.

Nádia: Também teve um episódio em que falaram sobre a questão do uso do banheiro, onde ela foi impedida de usar o banheiro feminino no trabalho.

(Roda de conversa sobre visibilidade, 2019).

Existe uma questão que pode ser feita a partir deste diálogo que é a questão da representação de determinadas características como uma ideia de denúncia de uma situação de injustiça frente ao reforço de um estereótipo.

Quando a personagem transgênero sofre situações de violência como a exclusão do mercado de trabalho e é impedida de usar o banheiro de acordo com sua identidade de gênero, esta situação está dentro de um contexto estereotipado para pessoas trans, mas a intencionalidade neste caso é de apresentar esta violência para que discussões possam ser feitas a respeito e para que mudanças possam ser propostas, em uma ideia de leitura e escrita desta realidade.

Entretanto, se uma situação como esta é apresentada sem uma proposta de discussão com uma postura crítica, corre o risco de reforçar um estereótipo e a pessoa transgênero passa a ser vista como sendo apenas possível de estar fora do mercado de trabalho e na impossibilidade de usar o banheiro que julga ser condizente com seu gênero. Como afirmou Adichie (2019, p.26), “A história única cria estereótipos e o problema com os estereótipos não é que sejam mentira, mas que são incompletos". Ana traz essa questão para o grupo durante a roda de conversa.

Ana: Onde está o limite entre dar visibilidade ou apenas por interesse ou marcar ainda mais o estereótipo?

Karla: Uma coisa que os estereótipos fazem e que é muito cruel é tirar a individualidade das pessoas.

Denner: Concordo. Seria limitar e dizer o que você pode ser e fazer e o que não pode. Entretanto, ninguém está isento de reproduzir discursos assim, sejam em brincadeiras ou expressões. Quando discutimos sobre inclusão pensamos bastante sobre isso, principalmente no trabalho com estudantes com deficiência. Ouvimos frases do tipo "se até o aluno com deficiência está 
fazendo, porque você não está?”.

Karla: É importante entendermos como cada pessoa é diferente. Saber os nossos limites e até onde podemos chegar e não ficar se comparando.

(Roda de conversa sobre visibilidade, 2019).

Com estas ideias sobre estereótipos em mente, realizamos uma atividade baseada no trabalho de Brito (2013). Como havia acontecido a mudança de algoritmo do Google para o termo lésbica, ao invés de buscarmos em revistas, fizemos a pesquisa usando o Google Imagens, na internet, para verificar como esta ferramenta estava retratando a comunidade LGBT+. Os participantes se dividiram em dois grupos: Grupo 1: Karla, Denner ${ }^{3}$ e Klaus e Grupo 2: Ana, Camila e Nádia.

Foi proposto que os grupos escolhessem um termo da sigla LGBT+ para fazer uma busca e tentar enquadrar os primeiros resultados como sendo positivos ou negativos. Além de visualizar a imagem, os grupos foram instruídos para fazer a leitura da legenda para ver ao que se referia. Foi utilizado os celulares dos próprios participantes (um em cada grupo) para fazer a busca e foram discutindo cada imagem individualmente e registrando. $\mathrm{O}$ grupo 1 decidiu dedicar-se a olhar para o termo: Travesti. O grupo 2 buscou pelos termos Gay e Lésbica.

Após os trabalhos dos dois grupos separadamente, houve um momento de compartilhamento e discussão de todos. Karla começou demonstrando uma indignação e surpresa ao ver que o termo Travesti estava muito ligado a notícias relacionadas com mortes.

Karla: Nossa, parece que todas são negativas.

Denner: Nosso grupo, pesquisando o termo "travesti" e olhando os 50 primeiros resultados, identificamos 5 positivas, 42 negativas e 3 notícias que não eram nem positivas e nem negativas. E vocês?

Ana: Nós não olhamos para os 50 primeiros resultados. Fomos até as 32 primeiras para o termo gay, sendo 28 negativas e 4 positivas. Depois, fomos para o termo lésbica e tivemos 11 negativas e 15 positivas. Isso deve ser decorrente da mudança do algoritmo,

\footnotetext{
${ }^{3}$ Como estávamos em um número pequeno de participantes e não tinha feito uma busca prévia pelos termos, decidi também ser participante e experienciar a atividade com os demais.
} 
pois achamos uma discrepância muito grande. Dentre as notícias negativas, muitas estavam relacionadas com mortes.

(Roda de conversa sobre visibilidade, 2019).

A Tabela 1 organiza os resultados para melhor visualização do leitor. Ele diz de uma situação de violência, uma vez que em todas as pesquisas são muitos os resultados negativos atrelados.

Tabela 1 - Resultados de buscas por três termos da sigla LGBT+

\begin{tabular}{ccccc}
\hline Termo \\
pesquisado & $\begin{array}{c}\text { Total } \\
\text { pesquisado } \\
(\mathbf{1 0 0 \% )}\end{array}$ & Positivos & Negativos & $\begin{array}{c}\text { Nem } \\
\text { positivos e } \\
\text { nem } \\
\text { negativos }\end{array}$ \\
\hline Travesti & 50 & $5(10 \%)$ & $42(84 \%)$ & $3(6 \%)$ \\
Gay & 32 & $4(12,5 \%)$ & $28(87,5 \%)$ & $0(0 \%)$ \\
Lésbica & 26 & $15(57,7 \%)$ & $11(42,3 \%)$ & $0(0 \%)$ \\
\hline
\end{tabular}

Fonte: Elaborado pelo pesquisador

A categoria nem positiva e nem negativa não caracteriza respostas neutras, mas representam resultados que não puderam ser enquadrados como sendo algo positivo ou negativo. No caso desta pesquisa em específico, os participantes entenderam três resultados desta forma para o termo travesti, pois eram imagens que eram usadas de forma incorreta para falar sobre drag queens ${ }^{4}$.

Apesar da mudança no algoritmo do Google ter feito com que encontrássemos mais resultados positivos $(57,7 \%)$ do que negativos $(42,3 \%)$, os números ainda preocupam. Conseguimos verificar com uma simples busca na internet que as pessoas LGBT+ ainda são retratadas em situações de vulnerabilidade social e atrelados a posições negativas.

Entretanto, esta discussão só foi possível, porque fizemos uso da matemática para analisarmos os resultados. A matemática, neste caso, nos ajudou a realizar uma leitura do mundo.

\footnotetext{
${ }^{4}$ Personagens criados por artistas que se transvestem para shows e eventos com o intuito geralmente profissional e artístico.
} 
Estes resultados, além de denunciarem uma realidade, reforçam os estereótipos.

Freire (1987), ao falar sobre o ato de ler, diz que este excede a leitura da palavra e tornase uma forma de interagir e conhecer o mundo. Neste exercício, a leitura que devemos fazer deve exceder um olhar superficial dos números e deve permitir que lancemos perguntas sobre esta realidade que está posta. Assim, podemos questionar, por que são estes os resultados e não outros? Por que dos 50 primeiros resultados para o termo travesti, 42 estão atrelados a notícias negativas?

Klaus: Das travestis só tem mortes.

Karla: Eu acho que muitas dessas notícias também tinham pessoas trans que foram chamadas de travestis, porque até as pessoas da mídia não tem clareza dos termos corretos.

Klaus: As notícias também estavam muito relacionadas com a prostituição.

Denner: Estavam relacionadas também com o uso incorreto de hormônios, por não poder pagar por um tratamento. A fila de espera da rede pública de saúde é gigantesca, então muitas pessoas acabam se suicidando ou se mutilando por não suportar estar em um corpo que não entendem como sendo deles. Alguma notícia chamou a atenção de vocês de forma específica?

Ana: Olhamos mais para aspectos gerais. As imagens da busca por "gays" muitas retratavam homens brancos e musculosos. Isso é um estereótipo. Nunca são retratados como um casal também.

(Roda de conversa sobre visibilidade, 2019).

As imagens sobre travestis, mostraram uma realidade enfrentada por esta população que muitas vezes é excluída do mercado de trabalho e recorrem a prostituição. São vítimas recorrentes dos crimes de ódio também. Dentre o grupo da comunidade LGBT+ estão em uma situação de vulnerabilidade maior, uma vez que possuem muitas vezes características físicas que deixa a identidade de gênero explícita no corpo.

Apesar de serem dados que denunciam a situação de um grupo, devemos estimular que os estudantes possam questionar o motivo de se apresentarem desta forma. Gutstein (2012) diz que para que possamos trabalhar em uma perspectiva de leitura e escrita de mundo com a matemática, devemos pautar nosso ensino em uma pedagogia da pergunta, onde os estudantes 
colocam-se em posição de suspeita em consonância com o que afirmou Freire (2000, p.90), "o mundo não é, o mundo está sendo". Ou seja, as transformações são possíveis e a realidade não é estática.

Depois de olharmos para os lugares em que as pessoas LGBT+ estavam sendo enquadradas, foi sugerida a pesquisa por outros em que possivelmente não estariam representados. A primeira busca feita foi pelo termo "casamento". Os resultados mostraram o casamento heterossexual e, principalmente com casais brancos.

Karla: $\quad$ Todos héteros e brancos.

Klaus: $\quad$ Apareceu apenas um casal negro, mas nenhum inter-racial.

(Roda de conversa sobre visibilidade, 2019).

Isso sugere para quem busca por este termo no Google Imagens que o casamento é uma realidade possível apenas para este tipo de casal representado nos resultados. A segunda sugestão de pesquisa foi pelo termo "família". Os resultados foram parecidos, seguindo um padrão tradicional de família composta por casais heterossexuais, brancos e com filhos.

Ana: Até aparecem casais negros, mas aquela configuração com pai, mãe e dois filhos. Você não vê uma mãe e os filhos ou apenas o pai e os filhos.

(Roda de conversa sobre visibilidade, 2019).

Uma última reflexão foi: que termos poderiam ser pesquisados e que encontrariam resultados com pessoas $\mathrm{LGBT}+$ ?

Ana: Prostituição. Sempre vai estar relacionado com o feminino, com a mulher, com a travesti.

Klaus: Feminino e periférico.

(Roda de conversa sobre visibilidade, 2019).

Neste sentido, podemos pensar acerca do que Ravn e Skovsmose (2019) discutem sobre o algoritmo do Google. A facilidade de buscas por termos que desconhecemos é grande na sociedade do conhecimento. Entretanto, precisamos estar atentos sobre os resultados dessa produção feita através de um algoritmo matemático. Esse mecanismo de busca é um dos 
principais canais de conhecimento atualmente, então alguém que desconhece sobre o assunto vai compreender que estes primeiros resultados retratam as principais características do que está buscando.

Sendo assim, faz sentido a preocupação na pesquisa pelo termo lésbica que era atrelado ao sexo. Para alguém que desconhece o tema, ao procurar sobre o assunto entendia que era natural relacionar dessa forma, já que o Google trazia essas informações. Pelos resultados desta atividade, vemos que para os termos relacionados com a comunidade LGBT+ ainda possuem marcas de estereótipos mostrando essa comunidade atrelada com situações negativas.

\section{Considerações Finais}

As reflexões sobre educação devem extrapolar os muros da escola. Olhando para os mais diversos espaços de aprendizagem, por exemplo uma casa de acolhimento LGBT+, vemos que uma pedagogia transformadora é aquela que inquieta, promovendo uma compreensão mais ampla do mundo em que vivemos. Reforçando os ideais de Freire (1987), todos temos potência para ensinar e aprender quando nos colocamos em posição de solidariedade.

As mídias possuem grande influência na construção de estereótipos que têm afetado diversos grupos, como por exemplo a comunidade LGBT+. Isso acontece quando apresentam apenas contextos atrelados à violência. Apesar de ser um retrato da realidade, adotar uma postura crítica ao estar com estes dados é essencial para que não seja apenas uma forma de reforçar preconceitos. Entretanto, mostrar que outas histórias são possíveis para esta população é importante, para que não seja contada uma história única sobre as pessoas LGBT+.

Sendo assim, vemos o potencial da matemática para uma leitura da realidade, desde que os estudantes sejam estimulados a questionar. Não concordar com estas violências e discriminações que foram socialmente postas para a comunidade LGBT+ é o primeiro passo para que mudanças possam ser feitas. Primeiro, devemos nos indignar (FREIRE, 2000) e, não nos rendermos ao fatalismo de que as coisas devem ser como são. Assim, podemos acreditar que ações são possíveis para colaborar na denúncia das injustiças e em suas superações para construirmos um mundo de mais possibilidades e menos barreiras.

A matemática pode auxiliar a compor essa construção de uma visão mais ampla de questões sociais, políticas, ambientais, econômicas, dentre outras. Entretanto, quando utilizada sem tornar visível seus processos para quem a utiliza, pode ser ferramenta para manipulação, 
por isso, as suas formas de utilização devem ser sempre questionadas.

Devemos estar conscientes das possibilidades da utilização da matemática na sociedade para construirmos juntos os conhecimentos pautados em uma consciência crítica e vigilante da sociedade e do mundo para promover mudanças em busca de uma sociedade melhor, não apenas para a comunidade $\mathrm{LGBT}+$, mas para todos.

\section{Referências}

ADICHIE, C. N. (2019) O perigo de uma história única. 1 ed. São Paulo: Companhia das letras.

ANVISA. (2004) RESOLUÇÃO-RDC/ANVISA n ${ }^{\circ} 153$, de 14 de junho de 2004. Disponível em: $<$ http://www.sbpc.org.br/upload/noticias_gerais/320100416113458.pdf $>$. Acesso em: 25 mar. 2020

BRITO, R. R. (2013) Educação Matemática \& Democracia: Mídia e Racismo. Anais do VII CIBEM. p.3355-3362.

CAMPOS, D.A.; PIRES, R. O. M. (2016) Pessoas LGBT em situação de rua: percepções acerca dos serviços de atenção básica no munícipio de Florianópolis/SC, Brasil. Anais do Congresso Internacional de Políticas Públicas para a América Latina.

ESTADÃO. (2020) O drama de quem nem tem água em casa. Disponível em: $<$ https://saude.estadao.com.br/noticias/geral,o-drama-de-quem-nem-tem-agua-emcasa,70003237499>. Acesso em: 19 de março de 2020.

FREIRE, P. (1987) Pedagogia do oprimido. 17. Ed. Rio de Janeiro: Paz e Terra.

FREIRE, P. (2000) Pedagogia da Indignação: cartas pedagógicas e outros escritos. 8. ed. São Paulo: Ed. UNESP, 2000.

FREIRE, P.; MACEDO, D. (2015) Alfabetização: leitura do mundo, leitura da palavra. Rio de Janeiro: Paz e Terra, 2015.

GARCIA, M. R. V. (2007) "Dragões”: gênero, corpo, trabalho e violência na formação da identidade entre travestis de baixa renda. São Paulo, 2007, 148p. Tese (Doutorado). Instituto de Psicologia. Universidade de São Paulo.

GRUPO GAY BAHIA. (2018) Relatório 2018: população LGBT morta no Brasil. Disponível em: <https:/grupogaydabahia.files.wordpress.com/2019/01/relat\%C3\%B3rio-decrimes-contra-lgbt-brasil-2018-grupo-gay-da-bahia.pdf>. Acesso em: 25 mar. 2020.

GUTSTEIN. E. (2006) Reading and writing the world with mathematics: toward a pedagogy for social justice. New York, NY: Routledge.

GUTSTEIN. E. (2003) Teaching and learning mathematics for social justice in an urban latino school. Journal for Research in Mathematics Education, v. 34, n. 1, p. 37-73.

GUTSTEIN. E. (2012) Reflections on teaching and learning mathematics for social justice in urban schools. In: A. A. Wagner e D. W. Stinson (Eds.) Teaching mathematics for social justice: conversations with educators. 
HARKOT-DE-LA-TAILLE, E. (2003) Ação moral e estereótipos culturais. In: ARANTES, V. A. (Org.). Afetividade na escola: alternativas teóricas e práticas. São Paulo: Summus. p.171-190.

MACHADO, R. W. G. (2015) População LGBT em situação de rua: uma realidade emergente em discussão. Revista EDUC-Faculdade de Duque de Caxias/Vol. 01 - No 03/Jan-Jun 2015. p.57-67.

O GLOBO. (2020) Google muda algoritmo para que palavra 'lésbica' não seja associada à pornografia nas buscas. Disponível em: <https://oglobo.globo.com/celina/googlemuda-algoritmo-para-que-palavra-lesbica-nao-seja-associada-pornografia-nas-buscas23866924>. Acesso em: 21 mar. 2020.

ORGANIZAÇÃO DAS NAÇÕES UNIDAS (ONU). (2020) Discriminação aumenta risco de jovens LGBTI irem morar na rua, dizem relatores. Disponível em: $<$ https://nacoesunidas.org/discriminacao-aumenta-risco-de-jovens-lgbti-irem-morar-narua-dizem-relatores/>. Acesso em 24 mar. 2020.

RAVN, O.; SKOVSMOSE, O. (2019) Connecting Humans to Equations: a reinterpretation of the Philosophy of Mathematics. Springer Nature Switzerland AG.

RIBEIRO, D. (2018) Quem tem medo do feminismo negro? São Paulo: Companhia das Letras.

SILVA, G. H. G. (2016) Equidade no acesso e permanência no ensino superior: o papel da educação matemática frente às políticas de ações afirmativas para grupos subrepresentados. 2016. 359 f. Tese (Doutorado em Educação Matemática - Instituto de Geociências e Ciências Exatas, Universidade Estadual Paulista, Rio Claro/SP.

TRATA BRASIL: SANEAMENTO É SAÚDE. (2020) ÁGUA. Disponível em: $<$ http://www.tratabrasil.org.br/saneamento/principais-estatisticas/no-brasil/agua>. Acesso em: 19 de março de 2020.

\section{Autor}

Denner Dias Barros. Doutorando do Programa de Pós-Graduação em Educação Matemática (PPGEM) pela Universidade Estadual Paulista Júlio de Mesquita Filho (Unesp) - Instituto de Geociências e Ciências Exatas da Unesp (IGCE/Unesp). Mestre em Educação Matemática, também pelo IGCE- Unesp. Possui graduação em Licenciatura em Matemática pela

Universidade Estadual Paulista Júlio de Mesquita Filho (UNESP) - Faculdade de Ciências e Tecnologia da Unesp (FCT/Unesp) e Pedagogia pela Faculdade Educacional da Lapa (FAEL).

Especialista em Libras: Prática e Tradução/Intérprete pela Universidade do Oeste Paulista

(Unoeste). 